\title{
RANCANGAN E-COMMERCE DAN PAYMENT API MIDTRANS UNTUK PRODUK UMKM (STUDI KASUS PADA RUMAH KEMASAN)
}

\author{
Edy Nasri $^{1}$, Ely Nuryani ${ }^{2}$, Nanang Agustiawan ${ }^{3}$ \\ Program Studi Teknik Informatika, Fakultas Ilmu Komputer, Universitas Banten Jaya, \\ Jl. Syeh Nawawi Albantani, Curug, Serang - Banten \\ E-mail: ${ }^{1}$ edynasri@ unbaja.ac.id, ${ }^{2}$ elynuryani@ unbaja.ac.id
}

\begin{abstract}
In the process of product marketing micro, small and medium enterprises on Shop Rumah Kemasan Pandeglang, still being done by marketing the product through the storefront and the goods are stored in the warehouse so that the search, counting of goods directly gets to the warehouse and recording is still using bookkeeping so that the service process for goods is slow, it often happens that goods are not found resulting in data loss, it is necessary to have a system that manages the transaction process for data collection and online sales in order to increase the number of sales and minimize data loss. The system that will be designed later is the e-commerce and payment API midtrans, this research was conducted to increase sales of micro, small and medium business products by providing a system that can be accessed by everyone anywhere and anytime so that in the system that will be built later, buyers no longer need to wait long to buy products and for payments there is no need to make cash payments just online, and for product sellers can speed up the sales process, organized data management. In the design and development stage of e-commerce applications, researchers use the Extreme Programming method, modeling using the UML which produces a software that is expected, and the language used in this development is the PHP programming language, the MYSQL database and for payments based on the Midtrans payment gateway application programming interface.
\end{abstract}

Keyword: API midtrans, e-commerce, extreme programming, payment, UML.

\section{PENDAHULUAN}

Pada Usaha Mikro Kecil dan Menengah (UMKM) Kota Pandeglang, produk yang dipasarkan berupa kain batik maupun baju batik. Dari proses penjualan ini masih melakukan dengan cara konvensional, dimana konsumen harus datang ke toko. Pemasaran penjualan batik di Toko Kemasan Pandeglang belum menjangkau wilayah yang luas atau bahkan banyak orang tidak tahu dengan produk batik wilayah Pandeglang yang pada intinya pemasaran hanya dilakukan untuk wilayah kota Pandeglang dan sekitarnya saja, maka dari itu 
dengan sistem yang akan dibangun nantinya pemasaran produk batik hasil UMKM Kota Pandeglang mampu dipasasrkan secara luas dan dapat dipesan kapanpun dan dimanapun.

Pada Toko Rumah Kemasan Pandeglang, proses penjualan masih dilakukan dengan cara menunggu pembeli datang ke toko begitu pun pembayaran dilakukan dengan tunai bayar di tempat, hal tersebut sangat disayangkan mengingat teknologi pada era sekarang ini mampu membuat proses jual beli yang dilakukan secara online sehingga jangkauan pembeli menjadi sangat luas dan hal tersebut akan sangat membantu dan memudahkan penjualan , untuk memasarkan produk-produknya agar lebih dikenal oleh masyarakat luas maka perlu dirancang aplikasi yang bersahabat dengan metode pengembangan extreme programming, sistem pemasaran dengan e-commerce dan metode pembayran dengan Midtrans. Metode extreme programming (XP) menawarkan tahapan dalam waktu relatif singkat sesuai dengan fokus yang akan dicapai pengembang (Rohmat, I. B., Adhie, T. P., \& Arif, R. E. 2020). E-commerce mungkin tampak seperti inovasi sederhana, tetapi lebih dari itu, penting untuk dikenali kekuatan yang harus diperhitungkan, dan sekarang menjadi pemimpin di pasar modern ini pada era digital (Pavankumar, R. T. 2018). Implementasi metode pembayaran akan sangat dinamis karena dengan Payment Gateway Midtrans mampu mengakomodasi seluruh jenis pembayaran digunakan di Indonesia. (Fariz, R. P., \& Nurudin, S. L. 2020).

1. Rumusan Masalah Penelitian:

1. Bagaimana Memanfaatkan teknologi informasi dalam penjualan produk UMKM kota pandeglang?

2. Bagaimana agar target pasar penjualan produk tidak hanya di Kota Pandeglang saja?

3. Bagaimana supaya produk UMKM kota pandeglang dapat dibeli kapanpun dan di manapun?

2. Tujuan Penelitian

Berikut ini merupakan tujuan yang akan dicapai pada penelitian, yaitu sebagai berikut :

1. Memudahkan pemilik UMKM untuk mengembangkan usahanya. 
2. Membuat model sistem informasi penjualan berbasis online.

3. Membuat aplikasi perancangan sistem yaitu untuk menampilkan informasi produk, informasi konsumen, informasi pemesanan dan pemayaran.

\section{METODE}

Metode penelitian merupakan cara yang digunakan untuk mencapai satu tujuan. Tujuan umum penelitian adalah untuk menyelesaikan masalah, maka langkah-langkah yang ditempuh harus relevan dengan masalah yang dirumuskan, adapun tahapan penelitian ini dibagi menjadi dua tahap sebagi berikut :

\section{Metode Pengumpulan Data}

Cara yang dilakukan dalam penelitian ini diantaranya:

a. Penelitian Lapangan

1) Observasi, pengumpulan data dengan cara mengamati secara langsung disekitar lingkungan kerja sebagai tempat objek penelitian.

2) Wawancara, pengumpulan data dengan cara wawancara langsung dengan mengajukan pertanyaan-pertanyaan yang keterkait dengan masalah-masalah yang akan dibahas dalam penelitian ini.

b. Penelitian kepustakaan

Cara pengumpulan data melalui kepustakaan secara teknis dengan melakukan membaca dan mempelajari buku-buku kepustakaan dan sumber jurnal serta sumber lainnya yang berkaitan dengan penelitian.

\section{Metode Pengembangan Sistem}

Ektreme Programming (XP) metode yang dikenal dengan technical how to atau bagaimana semua tim mengembangkan perangkat lunak secara efisien melalui berbagai prinsip dan teknik praktis pengembangan perangkat lunak. (Irmawati, C., \& Arief, R. 2019).

Programming Ektrem (XP) tipe dari agile development di mana mempunyai kelebihan kejelasan kebutuhan, mudah menyesuaikan teknologi, meyelesaikan kerumitan, kehandalan sistem yang dibangun, 
waktu pengerjaannya cepat dan jadwal pelaksanaanya baik. Proses XP dibagi 4 tahapan (Roger, S. P., \& Bruce, R. M. 2014) di bawah ini:

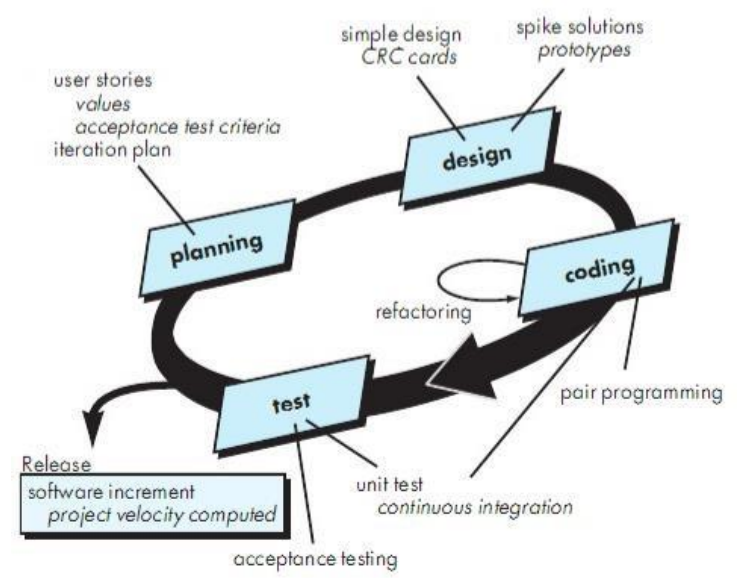

Gambar 1 Metodologi Programming Ektrim

\section{a. Tahapan-tahapan Pemrogramming Ektrim}

1) Planning, tahap ini dimulai membuat user stories yang menggambarkan keluaran, fitur, dan fungsi-fungsi dari aplikasi yang akan dibuat, kemudian diberikan bobot prioritas serta digrop untuk dilakukan proses kirim.

2) Design, tahapan ini akan menggunakan Spike Solution dimana untuk pembuatan desain langsung ke tujuannya, tahapan ini juga didukung refactoring dimana pengembangan perangkat lunak diubah sedemikian rupa dengan cara mengubah stuktur kode dan menyederhanakannya tapi tetap hasil mempertahankan kode yang ada.

3) Coding, tahapan ini merupakan tahapan proses koding yang diawali dengan membangun serangkaian unit test, kemudian pengembang akan berfokus untuk mengimplementasikannya diperkenalkan istilah Pair Programming dimana proses koding dilakukan secara berpasangan dimana kedua programmer saling bekerjasama untuk menulis koding. Untuk mendapat mempercepat penyelesaian masalah dan mempercepat jaminaan kualitas. 
4) Testing, tahap ini merupakan tahapan pengujian kode pada unit test. Tahapan ini juga dikenal dengan XP acceptance test (customer test) diamana tes ini langsung lakukan oleh kustomer yang berfokus pada fungsi-fungsi dan fiture sistem secara keseluruhan. Acceptance test dimulai dari user stories yang telah diimplementasikan. Pengujian software merupakan tahapan pengembangan yang sangat penting untuk memastikan perangkat lunak yang sudah atau sedang dikembangkan dapat berjalan sesuai dengan kebutuhan yang telah ditetapkan. (Irfan, A. A., Bagas, S., Rashad, K., Guruh, N., \& Yulianti. 2020)

\section{b. Perbandingan dengan metodologi pengembangan lainya}

Kreteria Pemilihan Metodologi kebutuhan pengguna (clarity user requirement), penguasaan teknologi (familiarity with technology), tingkat kerumitan sistem (system complexity), tingkat kehandalan sistem (system realibility), waktu pelaksanaan (short time schedules), dan visibilitas jadwal pelaksanaan (schedule visibility), (Alan, D., Barbara, H. W., \& David, t. 2016) dapat dilihat pada tabel di bawah ini:

Tabel 1. Kriteria Pemilihan Metodologi

\begin{tabular}{|l|l|l|l|l|l|l|}
\hline \multicolumn{1}{|c|}{$\begin{array}{c}\text { Kriteria Pengembangan } \\
\text { Sistem }\end{array}$} & $\begin{array}{c}\text { Waterf } \\
\text { all }\end{array}$ & Parallel & Phased & $\begin{array}{c}\text { System } \\
\text { Prototyp- } \\
\text { ing }\end{array}$ & $\begin{array}{c}\text { Threwaway } \\
\text { Prototyping }\end{array}$ & $\begin{array}{c}\text { Agile } \\
\text { Development } \\
\text { (XP, Scrum) }\end{array}$ \\
\hline Kejelasan kebutuhan pengguna & Buruk & Buruk & Baik & Baik Sekali & Baik Sekali & Baik Sekali \\
\hline Penguasaan teknologi & Buruk & Buruk & Baik & Buruk & Baik Sekali & Baik \\
\hline Tingkat kerumitan sistem & Baik & Baik & Baik & Buruk & Baik Sekali & Baik \\
\hline Tingkat kehandalan sistem & Baik & Baik & Baik & Buruk & Baik Sekali & Baik Sekali \\
\hline Waktu pelaksanaan & Buruk & Baik & Baik Sekali & Baik Sekali & Baik & Baik Sekali \\
\hline $\begin{array}{l}\text { Visibilitas jadwal } \\
\text { pelaksanaan }\end{array}$ & Buruk & Buruk & Baik Sekali & Baik Sekali & Baik & Baik Sekali \\
\hline
\end{tabular}

Agile Development yaitu pemrograman ekstrim (XP) berfokus kepada perampingan SDLC dengan banyak menghilangkan pemodelan dan dokumentasi overhead di mana menekankan kesederhanaan dan pengembangan aplikasi berulang, membangun sistem dengan cepat (Darmawan, S. B., Taghfirul, A. Y., \& Heri, A. 2016). Dari uraian di 
atas maka peneliti memilih menggunkan Metodologi pengembangan Agile Development yaitu pemrograman ekstrim (XP).

\section{Pemodelan Identifikasi Proses bisnis dengan Usecase diagram}

Memodelkan identifikasi proses bisnis dengaan usecase diagram untuk memahami fungsionalitas sistem, dimana elemen meliputi aktor, use case, batasan subjek dan relasilainya (Yasmiati, Suwarni, Desmiwati, \& Andi, S. 2021). Dengan menggunakan persyaratan yang dikumpulkan, tim mengidentifikasi proses bisnis dan lingkungan mereka menggunakan Usecase diagram (Alan, D., Barbara, H. W., \& David, t. 2016).

Untuk mengambarkan identifiaksi proses bisnis dalam penelitian ini adalah mengunakan usecase diagram. Usecase diagram digambarkan sebagai berikut:

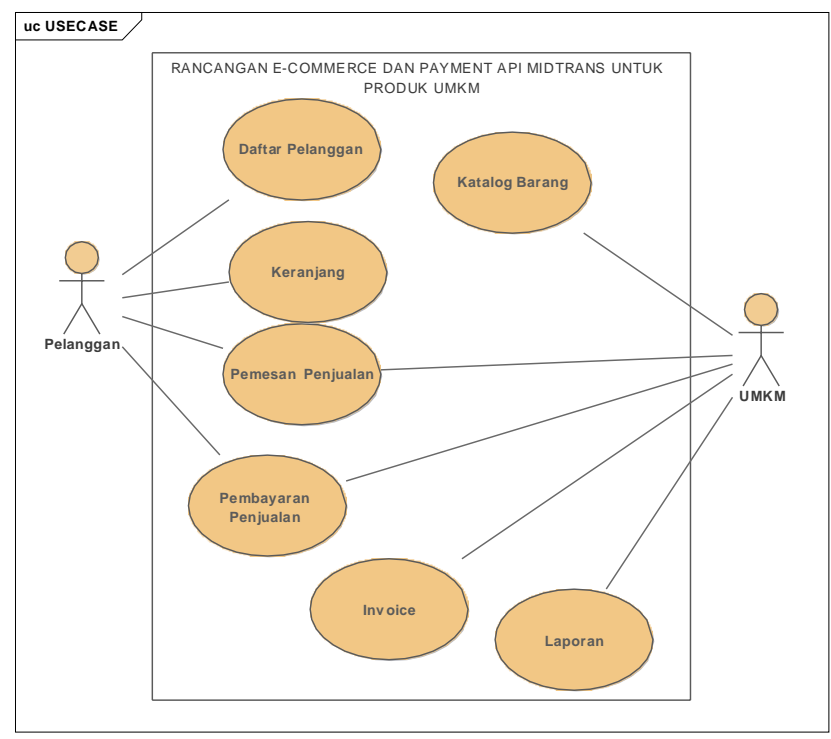

Gambar 2. Usecase Diagram

\section{Pemodelan Rancangan Desain Program dengan Class diagram}

Class adalah sekumpulan obyek yang memiliki atribut dan operasional yang sama (Munawar. 2018). Diagram kelas pada suatu sistem dapat memberikan gambaran hubungan antar kelas atau struktur sistem untuk mendefinisikan kelas-kelas yang akan dibuat untuk membangun sistem (Muhamad, S., \& Wahyu, N. 2020). Class diagram merupakan kelas 
yang digunakan untuk menunjukan interaksi antar kelas dalam sebuah sistem. Berikut ini merupakan class diagram dari sistem:

Gambar 3. Class Diagram

\section{Pemodelan Data}

Pemodelan data atau Entity Relational modling adalah metode perancang basis data dengan mengidentifikasi entitas dan hubungan antar entitas-entitas yang digambarkan dalam sebuah model (Indrajani. 2011). Model data fisik memungkinkan untuk mewakili bagaimana data didukung oleh DBMS yang diberikan, terdapat tiga model basis data yaitu model konseptual, logis, dan fisik (Andre, R., Afonso, S., \& Alberto, R. d. 2015).

Pemodelan Data merupakan suatau model data untuk menjelaskan hubungan antar tabel basis data yang mempunyai hubungan antar relasi, dibawah ini merupakan perancangan physical data model sebagai berikut: 
Gambar 4. Data Modeling

\section{HASIL DAN PEMBAHASAN}

\section{Implementasi Sistem}

Dari hasil impelementasi sistem yang dibagun yaitu mulai dari halaman login untuk akses ke web penjualan baik bagi user atau pengunjung dan admin, untuk bagian pengunjung diberikan fasilitas halaman keranjang, halaman pesanan, halaman detail pesanan, halaman pilih pembayaran adapun untuk bagian admin halaman kategori, halaman master barang, halaman invoice, halaman transaksi.

1) Menu Login

Untuk mengakses web penjualan online

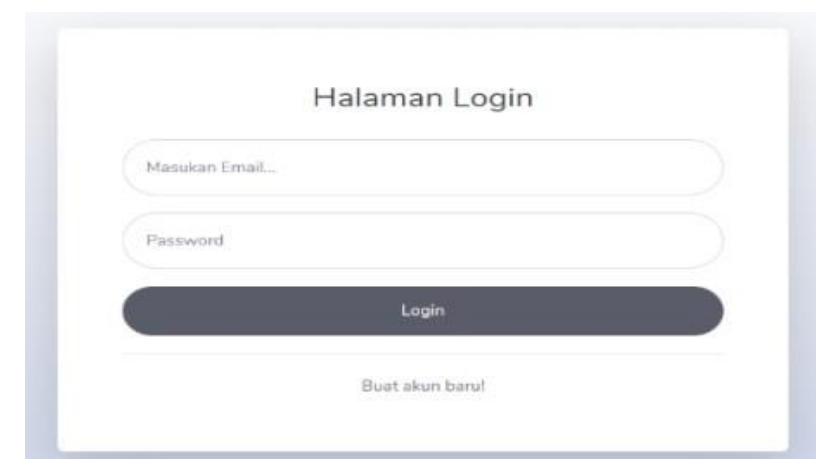

Gambar 5. Tampilan Halaman Login 
2) Menu Pengunjung

Halaman Utama pada menu pengunjung terdiri dari Home, Profil, Keranjang Belanja, Katalog seperti di bawah ini:

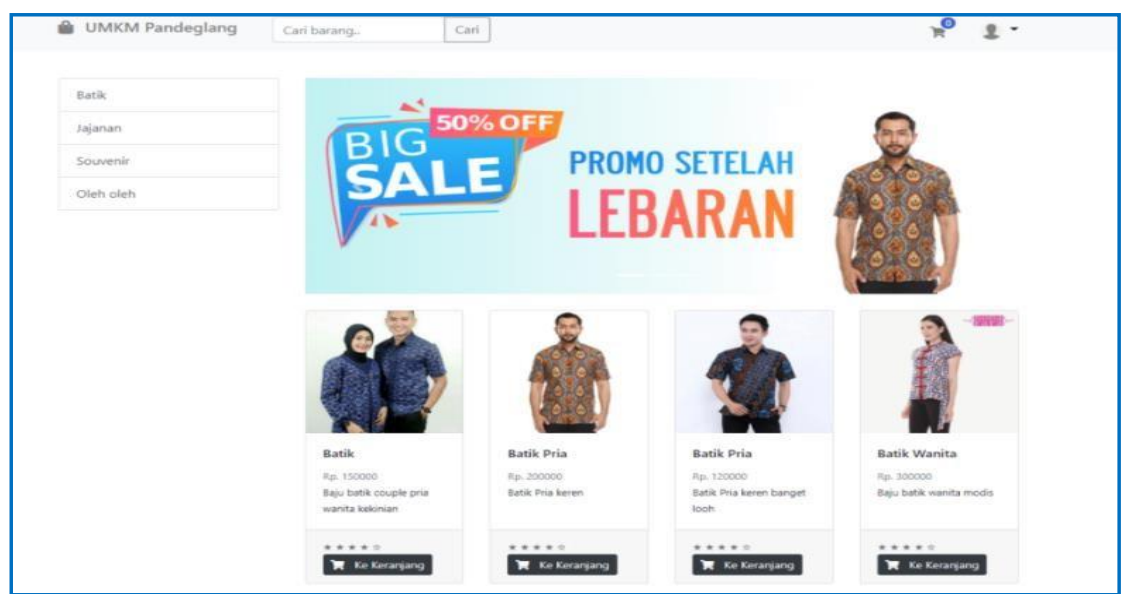

Gambar 6. Tampilan Halaman Pengunjung

3) Halaman Keranjang

Halaman keranjang ini untuk mencari barang yang akan di masukan form kekaranjang belanja, dengan mengklik ke tombol keranjang dari barang yang dipilih

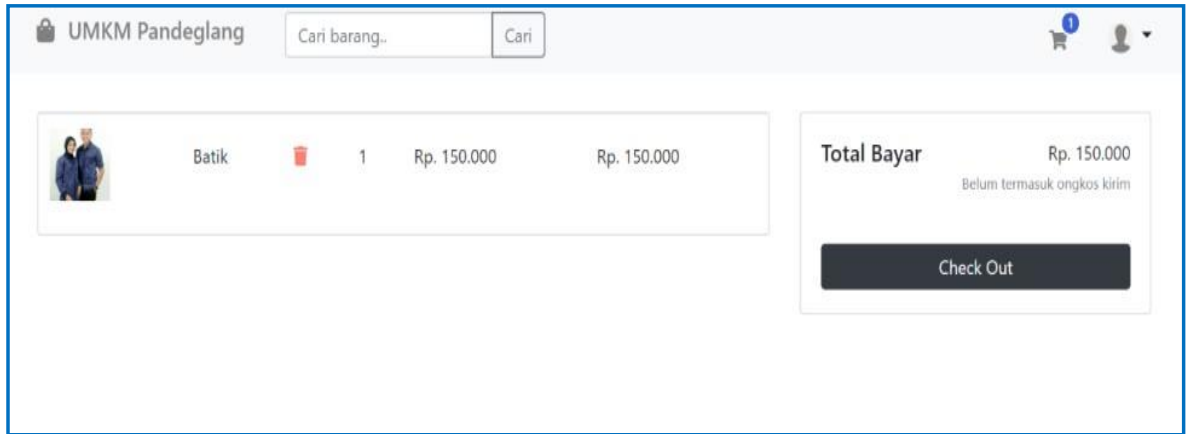

Gambar 7. Tampilan Form Keranjang

4) Halaman Pemesanan

Pada halaman ini merupakan berisikan form pemesanan, akan muncul setelah mengklik tombol check out, form sebagai berikut: 


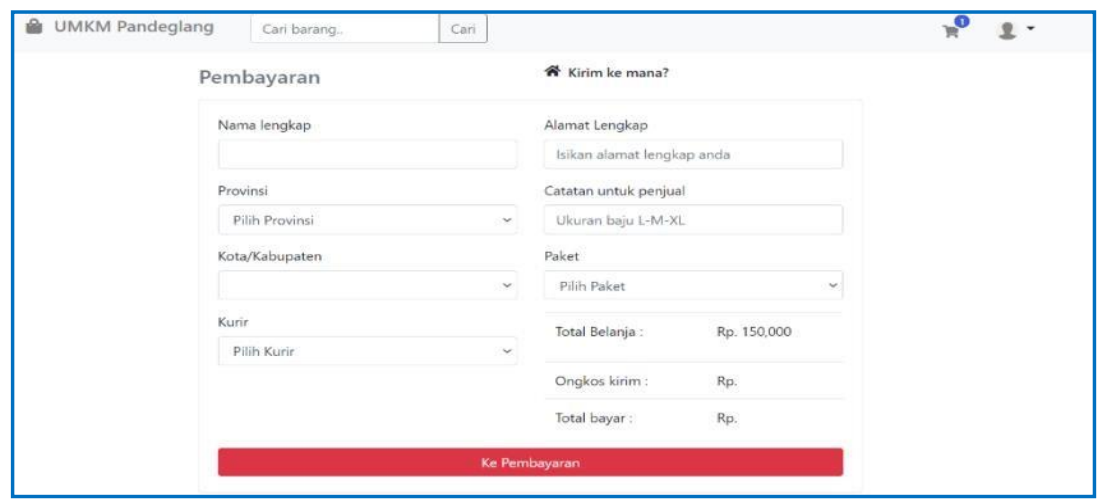

Gambar 8. Tampilan Form Pesan

Form detail pesan akan muncul setelah mengklik tombol kepembayaran.

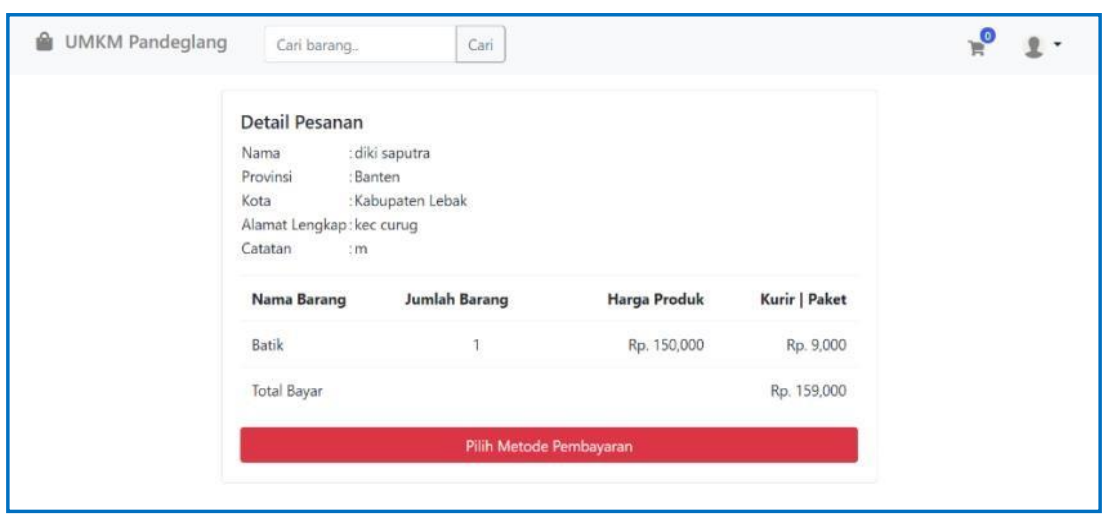

Gambar 9. Tampilan Form Pesan Detail

5) Halaman Pembayaran

Pembayaran merupakan form untuk memilih metode pembayaran yang digunakan, form ini akan tampil setelah mengklik tombol pembayaran.

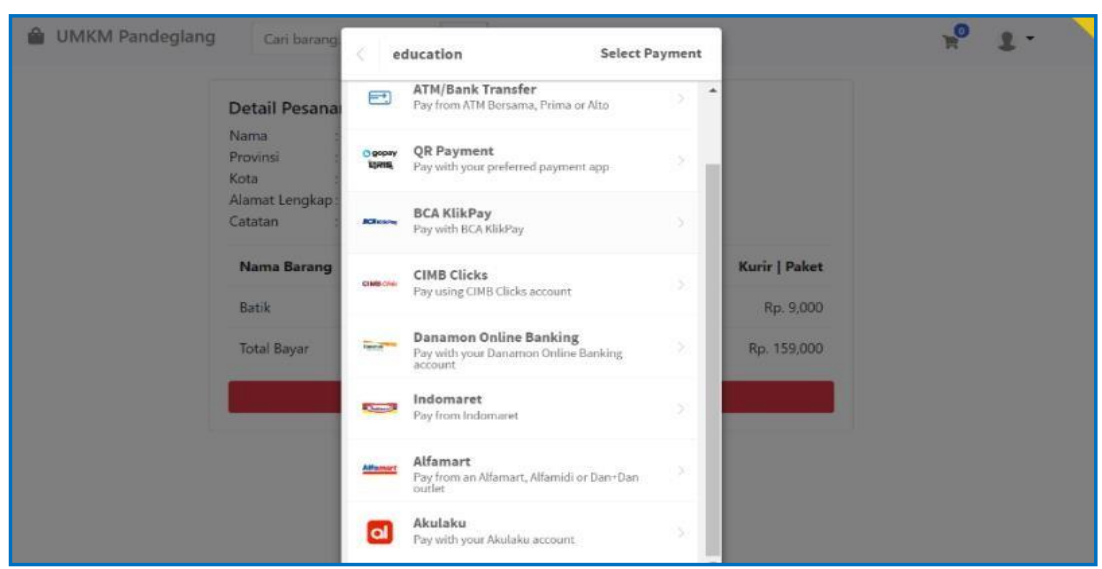

Gambar 10. Tampilan form pembayaran 
6) Halaman Utama Admin

Halaman utama admin merupakan halaman admin yang berisi barang, user, banner, kategori, proses transaksi (pesanan) dan laporan (laporan pembayaran, dan laporan pemesanan), logout.

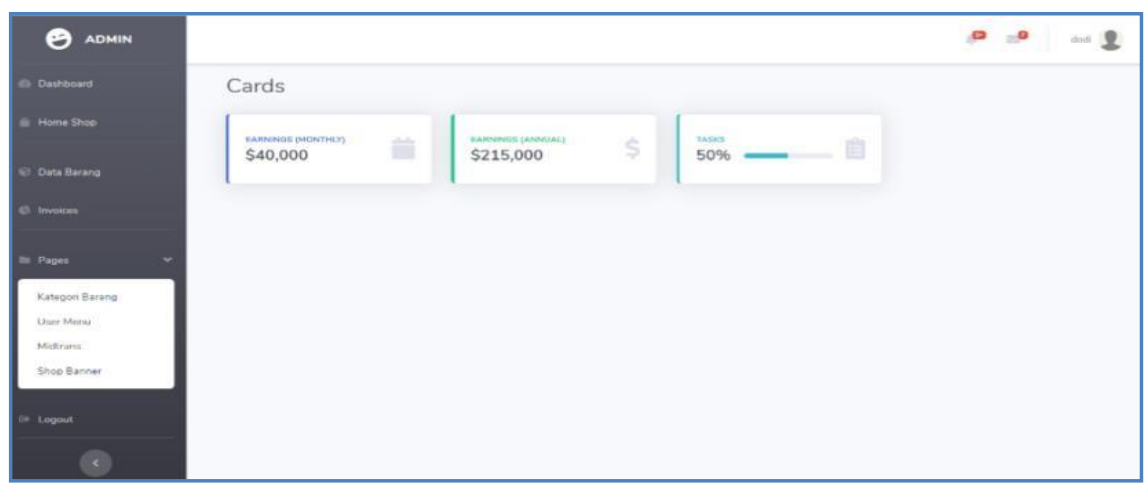

Gambar 11. Tampilan Halaman Utama Admin

7) Halaman Katalog

Halaman katalog ini merupakan Form yang digunakan untuk mengisi master kategori barang.

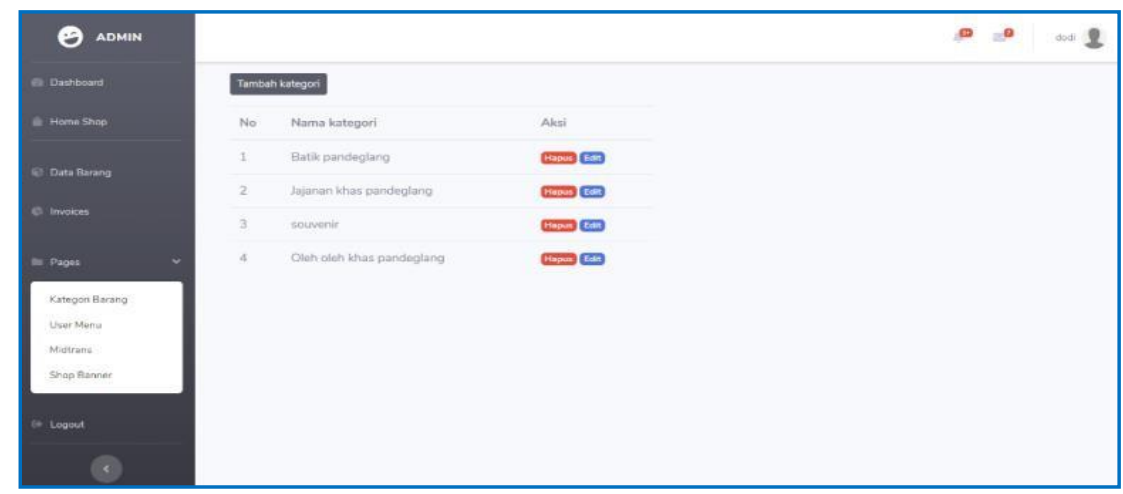

Gambar 12. Tampilan Katalog 
8) Halaman Form Barang

Halaman ini merupakan Form untuk menambahan data barang.

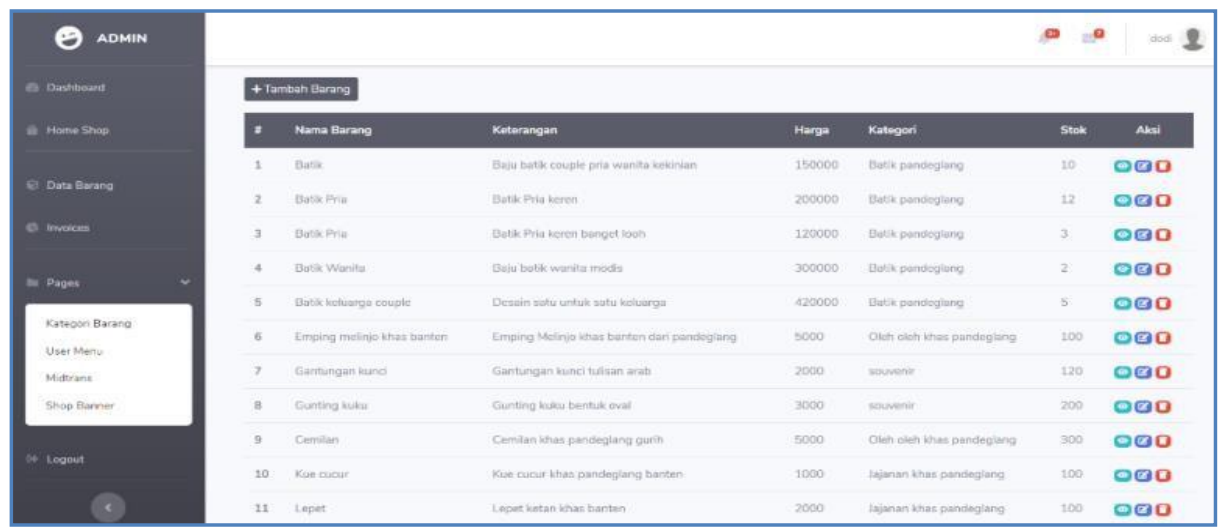

Gambar 13. Tampilan Form Barang

9) Halaman Invoice

Halaman ini meruakan Form ini tampil invoice untuk memvalidasi status pembayaran dari pesanan.

\begin{tabular}{|c|c|c|c|c|c|}
\hline () аомим & & & & & $\infty=1$ \\
\hline o buneser & Halmosea & Trmpalponer & Bats bover & sobus & abe \\
\hline a remenstan & 61 & 202000.0630 & 202000.07 & pendina & 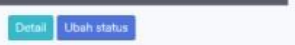 \\
\hline Date Bureng & 62 & 2020.0630 & 2020.070 .01 & ondina & 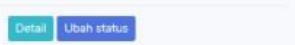 \\
\hline A morka & ๘ & 2020-06-30 & $20200-07.01$ & pending & 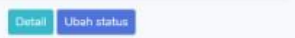 \\
\hline & $\approx$ & 2000.07 .07 & $202000.07,00$ & pending & Dowal Uow hatast \\
\hline Dreses & ${ }_{65}^{65}$ & 2020007.08 & 2020007009 & pendros & 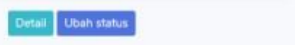 \\
\hline $\begin{array}{l}\text { unervenu } \\
\text { modrums }\end{array}$ & & & & & \\
\hline on wom & & & & & \\
\hline (c) & & & & & \\
\hline
\end{tabular}

Gambar14. Tampilan Form Invoice

10) Halaman Tansaksi

Halaman ini merupakan form transaksi pada halaman admin 


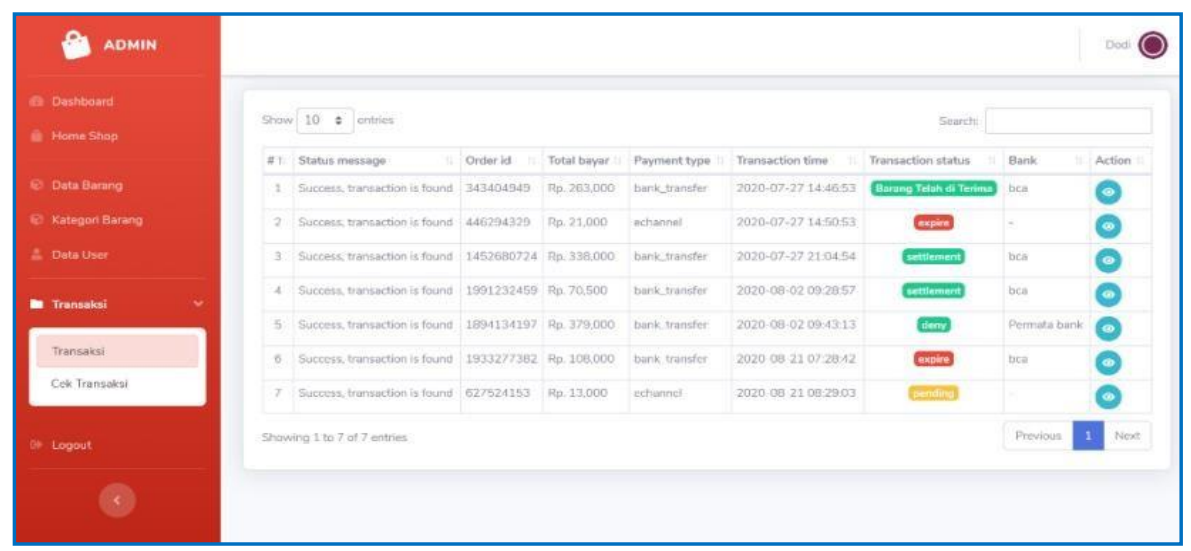

Gambar 15. Tampilan Form Transaksi

\section{Uji Coba dan Hasil}

Dalam tahapan pengujian sistem yang dibangun, metode yang gunakan peneliti untuk pengujian program adalah menggunakan black box testing dengan tujuan menemukan kesalahan atau ketidak sesuaian fungsifungsi didalam program yang diujikan.

Pengujian perangkat lunak dari segi spesifikasi fungsional tanpa menguji desain dan kode program untuk mengetahui apakah fungsi, masukan dan keluaran dari perangkat lunak sesuai dengan spesifikasi yang dibutuhkan, (Wahyu, N. C., Yulianingsih, \& Sri, M. S. 2018). Tabel Rancangan pengujian sistem yang di uji dengan teknik pengujian metode black box sebagai berikut:

Tabel 2. Pengelompokan pengujian blackbox

\begin{tabular}{|c|c|c|c|c|}
\hline No & Item Uji & Sekenerio Pengujian & Hasil yang diharapkan & $\begin{array}{l}\text { Hasil } \\
\text { Pengujian }\end{array}$ \\
\hline 1 & Halaman Login & $\begin{array}{l}\text { Masukan User \& } \\
\text { Password }\end{array}$ & $\begin{array}{l}\text { Berhasil Masuk ke menu } \\
\text { sesuai dengan otoritas } \\
\text { masing-masing. }\end{array}$ & Valid \\
\hline \multicolumn{5}{|c|}{ Halaman Pengunjung } \\
\hline 2.1 & Halaman Utama & & & \\
\hline 2.2 & Halaman Keranjang & $\begin{array}{l}\text { Pencarian Barang } \\
\text { Masukan Jumlah } \\
\text { Tombol Cekout }\end{array}$ & $\begin{array}{l}\text { Berhasil menampilkan } \\
\text { informasi barang } \\
\text { Berhasl dimasukan } \\
\text { Berhasil masuk halaman } \\
\text { pesanan }\end{array}$ & $\begin{array}{l}\text { Valid } \\
\text { Valid } \\
\text { Valid }\end{array}$ \\
\hline 2.3 & Halaman Pesanan & $\begin{array}{l}\text { Lengkapai data } \\
\text { Tombol Pembayaran }\end{array}$ & $\begin{array}{l}\text { Berhasil melengkapi data } \\
\text { Berhasil Masuk ke detail } \\
\text { pesan }\end{array}$ & $\begin{array}{l}\text { Valid } \\
\text { Valid }\end{array}$ \\
\hline 2.4 & $\begin{array}{l}\text { Halaman Detail } \\
\text { Pesanan }\end{array}$ & $\begin{array}{l}\text { Tombol Pilih Metode } \\
\text { Pembayaran }\end{array}$ & $\begin{array}{l}\text { Berhasil Menampilkan pilih } \\
\text { metode pembayaran }\end{array}$ & Valid \\
\hline
\end{tabular}




\begin{tabular}{|c|c|c|c|c|}
\hline 2.5 & $\begin{array}{l}\text { Halaman Pilih } \\
\text { Pembayaran }\end{array}$ & $\begin{array}{l}\text { Pilih metode } \\
\text { pembayaran }\end{array}$ & $\begin{array}{l}\text { Berhasil memilih } \\
\text { pembayaran }\end{array}$ & Valid \\
\hline \multicolumn{5}{|c|}{ Halaman Admin } \\
\hline 3.1 & $\begin{array}{l}\text { Halaman Menu } \\
\text { Kategori }\end{array}$ & $\begin{array}{l}\text { Tambah katagori } \\
\text { Edit katagori } \\
\text { Delete katagori }\end{array}$ & $\begin{array}{l}\text { Berhasil menambahkan } \\
\text { katagori } \\
\text { Berhasil mengedit katagori } \\
\text { Berhasil menghapus katagori }\end{array}$ & $\begin{array}{l}\text { Valid } \\
\text { Valid } \\
\text { Valid }\end{array}$ \\
\hline 3.2 & $\begin{array}{l}\text { Halaman Master } \\
\text { Barang }\end{array}$ & $\begin{array}{l}\text { Tambah master barang } \\
\text { Edit master barang } \\
\text { Delete master barang }\end{array}$ & $\begin{array}{l}\text { Berhasil menambahkan } \\
\text { master barang } \\
\text { Berhasil mengedit master } \\
\text { barang } \\
\text { Berhasil menghapus master } \\
\text { barang }\end{array}$ & $\begin{array}{l}\text { Valid } \\
\text { Valid } \\
\text { Valid }\end{array}$ \\
\hline 3.3 & Halaman Invoice & $\begin{array}{l}\text { Detail invoice } \\
\text { Ubah status }\end{array}$ & $\begin{array}{l}\text { Berhasil menampilkan detail } \\
\text { invoice } \\
\text { Berhasil merubah status }\end{array}$ & $\begin{array}{l}\text { Valid } \\
\text { Valid }\end{array}$ \\
\hline 3.4 & Halaman Transaksi & Mencari status & Berhasil menampilkan status & Valid \\
\hline
\end{tabular}

\section{KESIMPULAN}

Setelah melakuan penelitian tentang perancangan e-Commerce UMKM (Usaha Mikro Kecil dan Menengah) dapat menyimpulkan beberapa hal sebagai berikut yaitu:

1. Dengan menggunakan teknologi berbasis website dalam proses penjualan produk UMKM maka mempercepat pencarian, penyimpan data secara cepat dan akurat.

2. Proses pemesanan produk UMKM dapat dilakukan kapanpun dan di manapun serta target penjualan semakin meningkat.

3. Dengan menggunakan sistem ini pembeli bisa memilih produk-produk UMKM (Usaha Mikro kecil dan Menengah) secara online.

4. Transaksi Pembayaran Juga bisa dilakukan online dengan mengunakan API Minitrans.

\section{DAFTAR PUSTAKA}

Alan, D., Barbara, H. W., \& David, t. (2016). Systems Analysis and Design with UML 5th Edition. New Jersey: John Wiley \& Sons.

Andre, R., Afonso, S., \& Alberto, R. d. (2015). Data Modeling and Data Analytics: A Survey from a Big Data Perspective. Journal of Software Engineering and Applications, 8(12). 
Darmawan, S. B., Taghfirul, A. Y., \& Heri, A. (2016). Analisis Pemilihan Penerapan Proyek Metodologi Pengembangan Rekayasa Perangkat Lunak. Jurnal Teknologi Infromasi dan Komunikasi, 5(1).

Fariz, R. P., \& Nurudin, S. L. (2020). Pengembangan Aplikasi E-Commerce Menggunakan Payment Gateway Midtrans. Jurnal Pengembangan Teknologi Informasi dan Ilmu Komputer, 4(4).

Indrajani. (2011). Perancangan Basis Data dalam all inl. Jakarta: PT. Elex Media Komputindo.

Irfan, A. A., Bagas, S., Rashad, K., Guruh, N., \& Yulianti. (2020). Pengujian Black Box pada Aplikasi Sistem Kasir Berbasis Website Menggunakan Teknik Equivalence Partitions. Jurnal Teknologi Sistem Informasi dan Aplikasi, 3(2).

Irmawati, C., \& Arief, R. (2019). Penerapan Extreme Programming Pada Sistem Informasi Penjualan Pakaian Berbasis Web. Jurnal Inovtek Polbeng Seri Informatika, 4(2).

Muhamad, S., \& Wahyu, N. (2020). Pemodelan Diagram Uml Sistem Pembayaran Tunai Pada Transaksi E-Commerce. Jurnal Teknik Informatika Kaputama, 4(1).

Munawar. (2018). Analisis Perancangan Sistem Beorientasi Objek dengan $U M L$. Bandung: Informatika.

Pavankumar, R. T. (2018). E-commerce and Branding leads the Global Market into Digital Age. International Journal of Research in all Subjects in Multi Languages, 6(5).

Roger, S. P., \& Bruce, R. M. (2014). Software Engineering : A Practitioner's Approach. New York: McGraw-Hill Education.

Rohmat, I. B., Adhie, T. P., \& Arif, R. E. (2020). Implementasi Metode Pengembangan Sistem Extreme Programming (XP) pada Aplikasi Investasi Peternakan. Jurnal Sistem dan Teknologi Informasi, 8(3).

Wahyu, N. C., Yulianingsih, \& Sri, M. S. (2018). Pengujian Black Box Testing Pada Aplikasi Action \& Strategy Berbasis Android Dengan Teknologi Phonegap. Satuan Tulisan Riset dan Inovasi Teknologi, 3(2). 
Yasmiati, Suwarni, Desmiwati, \& Andi, S. (2021). Pemodelan Proses Bisnis PMB Menggunakan Pendekatan Berorientasi Objek berbasis Prototyping dengan Metodologi RAD. Jurnal Teknologi Informasi, 7(1). 